\title{
Multi-lead electrocardiogram in relation to serum enzymes in acute myocardial infarction
}

\author{
Andrzej Krotkiewski, Janina Gajewska-Lipka, Jacek Szelemetko, and Jaroslaw Ruszkowski \\ From Department I of Medicine, Central Clinical Hospital, Warsaw, Poland
}

This study was made in an attempt to analyse the $S T$ segment deflection on the map of a multi-lead chest electrocardiogram, and the changes in that area in the course of time. The deflection was regarded as an indication to the extent of the infarction. The sum of ST elevation $\left(\sum S T\right)$ was considered as a measure of the extent of tissue damage. A relation was sought between these parameters and the activity of certain serum enzymes.

The prognosis of myocardial infarction depends to some extent on its site and size, both of which, however, are sometimes difficult to assess.

Maroko et al. (1972) determined the extent of the ischaemic lesion caused by experimental ligation of the coronary artery in dogs by recording the electrocardiogram from several points of epicardium. These recordings were subsequently compared to the multi-lead electrocardiograms taken from the surface of the chest and a reasonable similarity was found as regards the size of the lesion.

Kjekshus, Maroko, and Sobel (1972) performed similar investigations in order to elucidate the relation between changes in the ST segment in epicardial recordings and the cell injury as reflected by creatinine phosphokinase (CPK) depletion in different layers of the muscle of the left ventricle. Regions of acute ischaemia were delineated with the use of epicardial electrocardiograms from multiple sites, I5 minutes after coronary occlusion. The authors found a relation between ST elevation and in CPK depletion.

The same authors also performed human studies assessing the size of the ischaemic area of the heart muscle by multi-lead electrocardiograms. It has been proved that the area on the chest surface where raised ST segments are recorded is in some way a projection of the ischaemic lesion, thus reflecting its size: provided that the chest electrocardiogram is a multi-lead one. Body surface isopotential maps of the QRS have been reported previously by Spach et al. (1966) and Tazawa and Yoshimoto (1969) in children. The same was true for the R-ST segment (Rakita et al., 1954; Sayen et al., 1958; Braunwald

Received 30 March 1973. et al., 1969). The surface mapping of the RS-T segment was performed by Reid, Pelides, and Shillingford (1971), and Taccardi (1963) in normal adults.

Apart from these experimental investigations we have been unable to find any human studies on the precise comparison of the size of the area depicted by ST elevation (or the sum of ST elevations: $\Sigma$ ST) with the serum enzyme changes in patients with acute myocardial infarction.

The present study is an attempt to analyse such a relation and its behaviour in time.

\section{Subjects and methods}

Twenty men aged $4 \mathrm{I}-72$ years admitted to the Intensive Care Unit with a clinical diagnosis of acute myocardial infarction were studied. The patients studied were those who were admitted to our hospital within the first $\mathbf{7 2}$ hours after the beginning of anginal pain, usually within Io to 15 hours.

Electrocardiograms were recorded in the supine position with Mingograph 8I apparatus at $50 \mathrm{~mm} / \mathrm{sec}$ recording speed. The electrocardiographic examination consisted of a routine I2-lead electrocardiogram followed by multi-lead recordings from the chest. These recordings were taken on admission and repeated every day for a week and then once a week for 5 or 6 weeks.

Multi-lead recordings were taken from 72 electrodes (Wilson type) arranged in 8 transverse rows, 9 electrodes in each row, from the 2nd to the 6th intercostal. The transverse rows were designated as A, B, C ... H, A from above down. The longitudinal columns were arranged with the figures I to 9, starting from the right mid-clavicular line and proceeding to the left midaxillar line (Reid et al., 197I). The position of each electrode was permanently marked on the skin to make sure 
that the arrangement of electrodes on repeated recordings would be exactly the same. The distances between individual electrodes in every particular patient were the same in both directions, but depended on the size of the chest.

In the multi-lead electrocardiogram the elevation of the ST segment was analysed. The deflection of the ST segment from the isoelectric line was measured exactly $0.06 \mathrm{sec}$ after the $S$ wave. Segments TP or PQ were considered as the isoelectric reference. The values so obtained were plotted on a blueprint of the electrode map. Elevation of ST was measured in millimetres ( $1 \mathrm{~mm}=0 \cdot \mathbf{I}$ $\mathrm{mV}$ ), and the sum of ST elevations ( $\Sigma$ ST) was considered as a measure of the extent of tissue damage. The number of sites where the ST elevation was more than $0.5 \mathrm{~mm}$ represented the size of the ischaemic area. The points at which the ST deflection was the same were connected by a contour line. Such maps depicting the areas of similar deflection of the ST segment have been designated isodeflectograms.

In all patients determinations were made of GOT, GPT, CPK, and LDH, parallel to the electrocardiographic examinations.

Blood was sampled for initial enzyme determination, 2 to 16 hours after admission and subsequently at 24hour intervals, on the 2nd, 3rd, 4th, 5th, and 6th day. Then the enzyme determinations were repeated at weekly intervals for 5 to 6 weeks. Enzyme determinations were made in parallel with electrocardiogram multi-lead recordings. SGOT, SGPT, and LDH were estimated using the Behringer-Mannheim reagent kits (Reitman and Frankel, 1957; Wróblewski and LaDue, 1955), and the results were expressed in international units $(\mathrm{mU} / \mathrm{ml})$.

CPK was assessed according to the method of Häcker, Krüger and Augustin (1967). The same scheme of blood sampling intervals and of electrocardiographs was strictly followed in all patients, the only exception being the initial examinations which differed to some extent regarding the time elapsing from the beginning of the attack.

\section{Results}

In 20 patients 193 multi-lead electrocardiograms were recorded and evaluated by means of isodeflectogram curves.

The anterior wall of the heart muscle was involved in Io patients, posterolateral in 5, posterior in 4 , and I patient had multifocal infarction.

In all Io patients with infarction of the anterior wall a similar electrocardiographic pattern was seen. The ST elevation ranged from 0.5 to $10 \mathrm{~mm}$. The sum of ST ( $\Sigma$ ST) elevations in 6 patients conspicuously diminished as soon as the day after admission, e.g. from 239 to $123 \mathrm{~mm}$. In 4 patients in whom imminent infarction was diagnosed the sum of ST elevations was initially little increased with infarction. In all to patients the sum of ST elevations gradually decreased in the 5 th or 6th week: ST elevation, less than I $\mathrm{mm}$, was seen only in few recordings.

Drawings were made representing, graphically, the results of multi-lead electrocardiograms. In infarction of the anterior wall the contour line connecting the points with the highest elevation of the ST segment was surrounded by contours representing ST elevations of lower and lower grade. On repeated examinations following the clinical course, the original picture changed usually by stepwise diminution and then disappearance of the central area of highest ST elevation. A good correlation with decreasing activities of serum enzymes was found.

It has to be emphasized that the enlarging of the infarcted area was accompanied by spreading of isodeflectographic contours and by increasing the sum of ST elevation ( $\Sigma S T)$. There was a very good correlation between the results of multi-lead electrocardiography and the clinical picture and serum enzyme activity, whereas the routine I2-lead electrocardiogram revealed only inconspicuous changes or none.

Fig. I-4 illustrate such changes. For reasons of clarity only two enzymes (LDH and GOT) were plotted.

Patient S.K. aged 42 (Fig. Ia). Infarction of the anterior wall. Ventricular fibrillation, clinical death, effectively resuscitated. Fig. Ia presents the isodeflectograms made on the Ist, 28th, and 125th day of the infarction. Differently marked curves represent the isodeflectographic contours. On the first day the area of ST elevation was the largest as compared to the following examinations, as was the area of maximal ST elevation (IO $\mathrm{mm}$ ) covering a great central part of the picture. The isodeflectographic contours shrank on the 28th and 125th day. On the 125th day no elevations higher than $3 \mathrm{~mm}$ were found.

Fig. Ib refers to the same patient. The sum of ST elevations is compared with the activity of serum GOT and LDH. The sum of ST elevations is drawn as a continuous line, SGOT as a dotted line, and LDH as a dashed line. Normal values of SGOT are $\mathrm{I2} \mathrm{IU} / \mathrm{ml}$, and for $\mathrm{LDH} 195 \mathrm{IU} / \mathrm{ml}$.

On the first day after infarction the sum of ST elevations was $239 \mathrm{~mm}$, SGOT $50 \mathrm{IU} / \mathrm{ml}$, and LDH 100 $\mathrm{IU} / \mathrm{ml}$. The highest SGOT activity occurred on the second day, 93 IU, the highest LDH activity on the fourth day, $299 \mathrm{IU} / \mathrm{ml}$. At the same time the sum of ST elevations showed a decrease and then all three values decreased gradually.

Patient K.W., aged 56 (Fig. 2a). Infarction of the anterior wall. Isodeflectograms made on the Ist, 4 th, and 30th day of the attack show an enlargement of the particular isodeflectographic contours and the values of ST elevation. This correlates well with the clinical course: recurrence of severe retrosternal pain and a rise of serum enzymes activity. On the 3oth day there was a significant diminution of the abnormalities. 


\section{S.K. Age: 42}
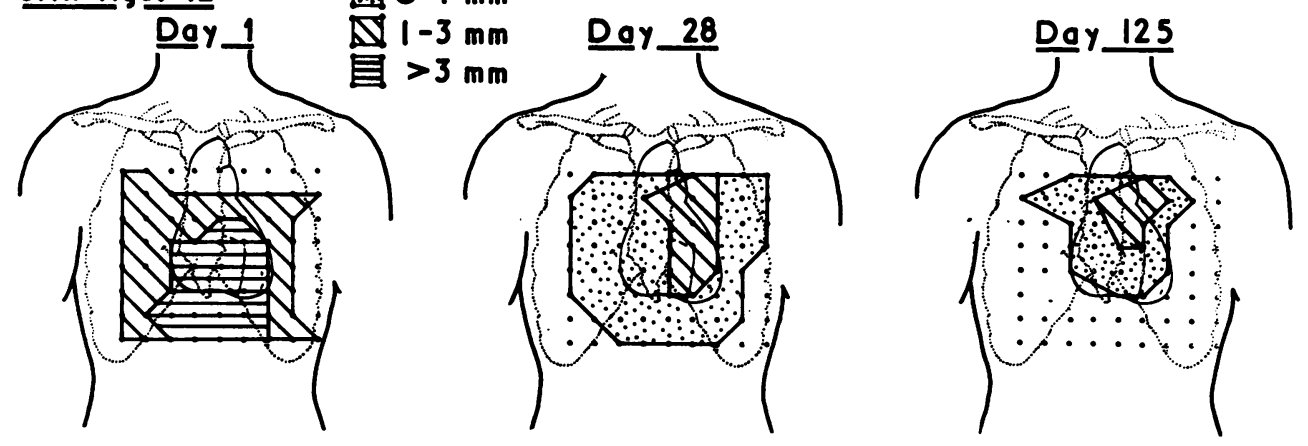

(a)

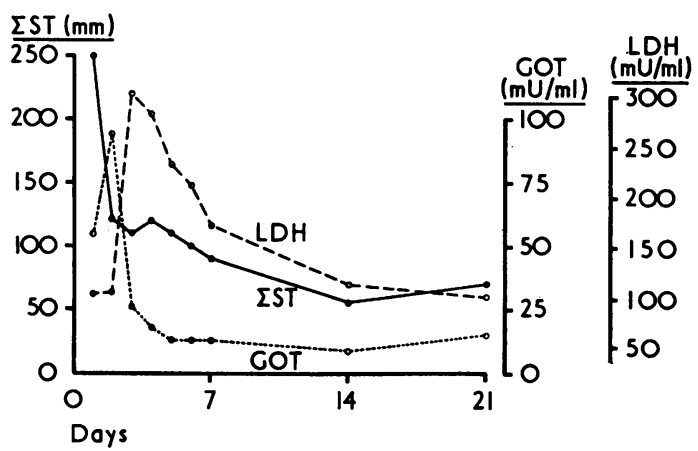

(b)

Fig. 2b shows the curve of the ST elevation sum together with the curves of SGOT and SLDH. Here again the rise of three parameters is seen on the fourth day with subsequent gradual lowering.

Patient K.R., aged 44, anterior myocardial infarction. Fig. 3 shows isodeflectograms made on the Ist, 7 th, and 29th day. A conspicuous decrease is seen in the area and absolute values of ST elevation. The last picture shows only a minute central spot of ST elevation not exceeding I $\mathrm{mm}$.

Patient S.A., aged 48 (Fig. 4a). Posterolateral infarction. The dominant change in this patient with posterior myocardial infarction was ST segment depression. The enzyme changes however were evident and parallel to the depression of the ST segment, as they were parallel to the ST elevation in the other cases. The isodeflectogram presented in Fig. 4a shows the area of ST depression in the left upper part of the map. The same examination on the 7th day shows spreading of the isodeflectographic contours and an increase of the values for ST depression. In the clinical course there was a recurrence of pain, and an increase of serum enzyme activity. On the 35th day all the parameters mentioned diminished conspicuously.

Fig. $4 \mathrm{~b}$ refers to the same patient. Comparison of the sum of the curves of ST depression (at the bottom), of 
994 Krotkiewski, Gajewska-Lipka, Szelemetko, and Ruszkowski

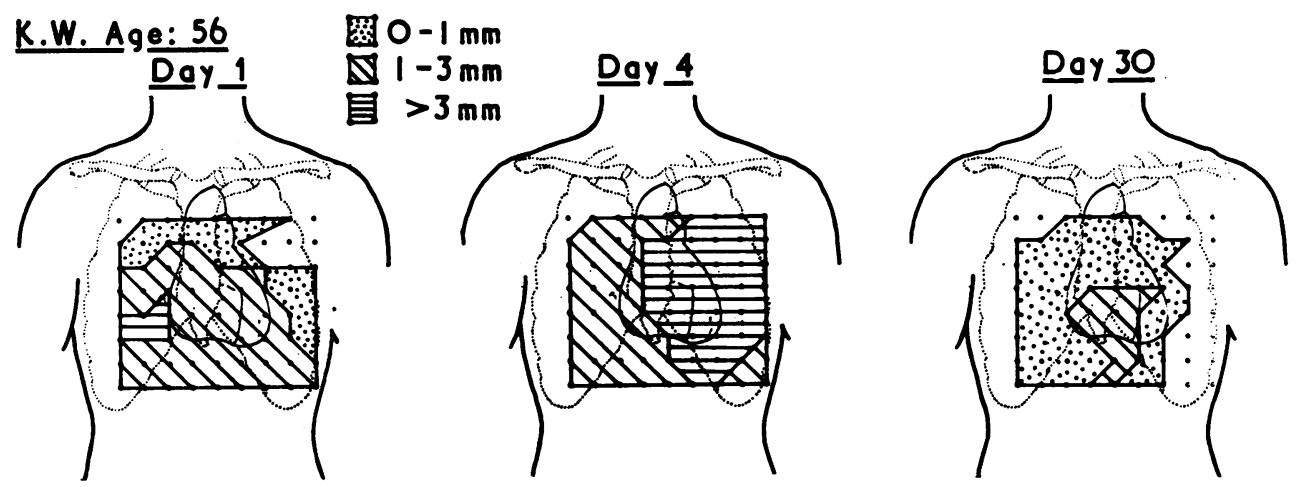

(a)

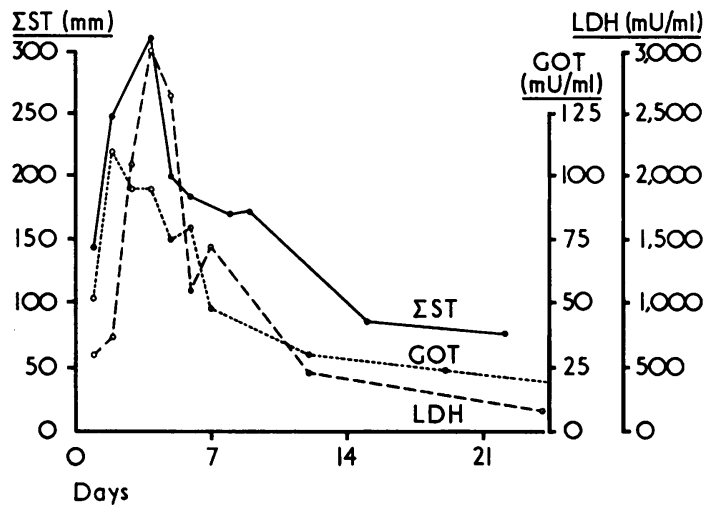

(b)

have proved it by comparing the clinical and biochemical data with the sum of ST elevations as shown in Fig. I-4. The earlier experiments of Kjekshus et al. (1972) seem to justify our assumption.

We believe that multi-lead electrocardiography

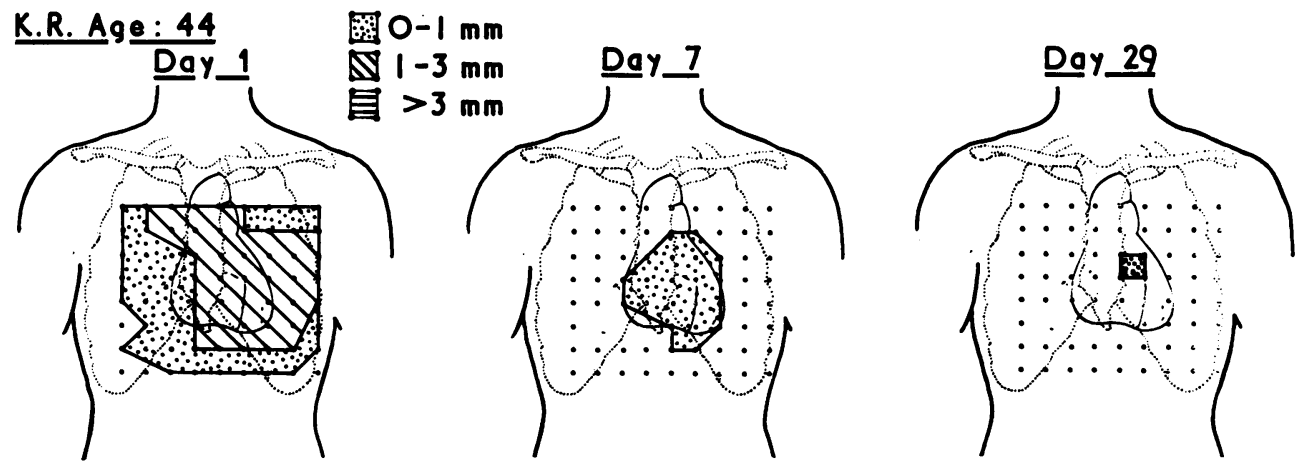

FIG. 3 Anterior myocardial infarction (K.R. aged 44). Isodeflectograms on the Ist, 7 th, and 29th day. A conspicuous decrease of the area and absolute value of ST elevation. On the 29th day only a very small area of $S T$ elevation.

FIG. 2 (a) Anterior myocardial infarction (K.W. aged 56). Isodeflectograms on the Ist, 4th, and 30th day. On the 4th day enlargement of the ST elevation area and significant diminution on the 3oth day. (b) The same patient. Comparison of the $\Sigma S T$ with the SGOT and SLDH activity (Legend as Fig. Ib). On the 4th day the rise of three parameters with subsequent gradual lowering.

analysis is a valuable, noninvasive method for determining and evaluating ischaemic heart damage. This method may perhaps enable the study of the effect of drugs on the size and severity of the infarction (Maroko et al., 197I). Pelides et al. (1972) used the surface mapping of the ST segment to evaluate 


\section{S.A. Age: 48}
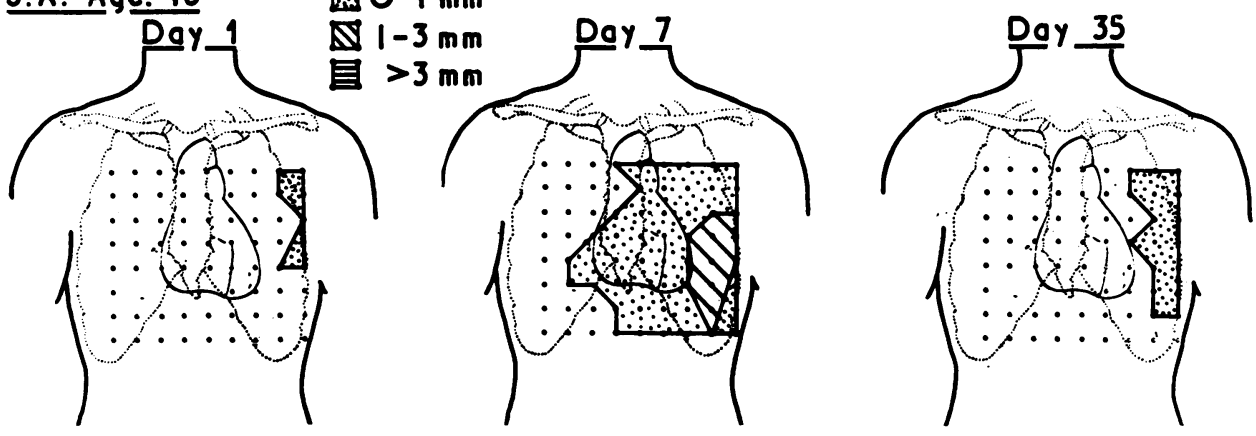

(a)

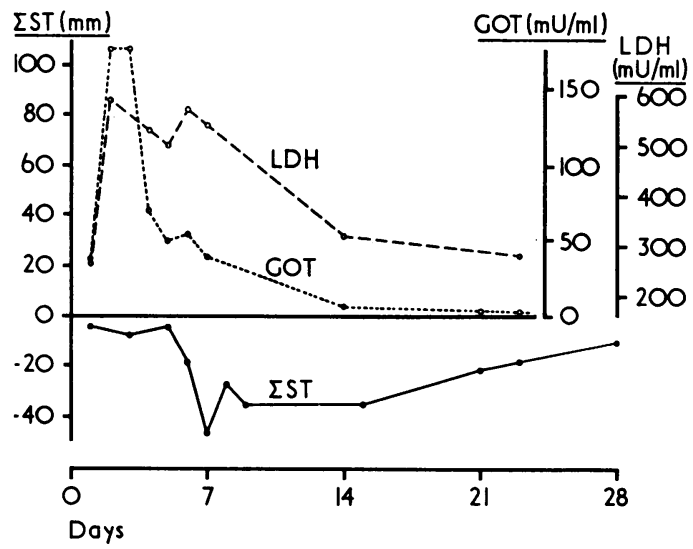

(b)

FIG. 4 (a) Posterolateral infarction (S.A. aged 48). Isodeflectograms presented only depression - enlargement of the $S T$ depression area and its considerably diminished values on the 35th day. (b) The same patient. Comparison of the curves of $S T$ depression sum (bottom) and SGOT, SLDH value. A distinct second rise of parameters followed by gradual subsiding (Legend as Fig. Ib).

in evaluating the course of myocardial infarction.

area in myocardial infarction; observing after practolol administration the decrease in the extent and height of the ST segment elevation they suggested that it could be used as an index of the extent and degree of ischaemia. The standard electrocardiogram may be normal in acute myocardial infarction (Johnson et al., 1959) and there may be a delay in appearance of the electrocardiographic features (Short 1968, 1970). Probably the multi-lead electrocardiogram will be of value in diagnosing cases of myocardial infarction with a normal standard electrocardiogram. It has to be stressed that there are certain limitations in the method at present, because satisfactory results are obtained only when analysing anterior myocardial infarction. The problem of posterior localization needs further study.

It is hoped that further investigation of multilead electrocardiography with isodeflectographic analysis will develop better and simpler techniques of examination and be of assistance to the physician 
cardial infarction cannot reliably be interpreted with the present arrangement of electrodes.

\section{References}

Braunwald, E., Covell, J. W., Maroko, P. R., and Ross, J. (1969). Effects of drugs and of counterpulsation on myocardial oxygen consumption: observations on the ischaemic heart. Circulation, 39-40, Suppl. 4, p. 220.

Hä cker, M. R., Krüger, E., and Augustin, H. W. (1967). Ǔber eine einfache Methode zur Bestimmung der Kreatkinase (ATP: Kreatin-Phosphotransferase. E. C. 2.7.3.2). Zeitschrift für medizinische Labortechnik, 8, 259.

Johnson, W. J., Achor, R. W. P., Burchell, H. B., and Edwards, J. E. (1959). Unrecognized myocardial infarction. A clinicopathologic study. Archives of Internal Medicine, I03, 253.

Kjekshus, J. K., Maroko, P. R., and Sobel, B. E. (1972). Distribution of myocardial injury and its relation to epicardial ST-segment changes after coronary artery occlusion in the dog. Cardiovascular Research, 6, 490.

Maroko, P. R., Kjekshus, J. K., Sobel, B. E., Watanabe, T., Covell, J. W., Ross, J., and Braunwald, E. (197I). Factors influencing infarct size following experimental coronary artery occlusions. Circulation, 43, 67.

Maroko, P. R., Libby, P., Covell, J. W., Sobel, B. E., Ross, J., Jr., and Braunwald, E. (1972). Precordial ST segment elevation mapping: an atraumatic method for assessing alterations in the extent of myocardial ischemic injury. American fournal of Cardiology, 29, 223.

Pelides, L. J., Reid, D. S., Thomas, M., and Shillingford, J. P. (1972). Inhibition by beta-blockade of the ST segment elevation after acute myocardial infarction in man. Cardiovascular Research, 6, 295.

Rakita, L., Borduas, J. L., Rothman, S., and Prinzmetal, M. (1954). Studies on the mechanism of ventricular activity. XII. Early changes in the RS-T segment and QRS complex following acute coronary artery occlusion: experimental study and clinical applications. American Heart fournal, 48, 35I.
Reid, D. S., Pelides, L. J., and Shillingford, J. P. (I97I). Surface mapping of RS-T segment in acute myocardial infarction. British Heart fournal, 33, 370.

Reitman, S., and Frankel, S. (1957). A colorimetric method for the determination of serum glutamic oxalacetic and glutamic pyruvic transaminases. American fournal of Clinical Pathology, 28, 56.

Sayen, J. J., Sheldon, W. F., Peirce, G., and Kuo, P. T. (I958). Polarographic oxygen, the epicardial electrocardiogram and muscle contraction in experimental acute regional ischemia of the left ventricle. Circulation Research, 6, 779.

Short, D. (1968). Value and limitations of electrocardiogram in diagnosis of slight and subacute coronary attacks. British Medical fournal, 4, 673.

Short, D. (1970). The earliest electrocardiographic evidence of myocardial infarction. British Heart fournal, 32, 6.

Spach, M. S., Silberberg, W. P., Boineau, J. P., Barr, R. C., Long, E. C., Gallie, T. M., Gabor, J. B., and Wallace, A. G. (1966). Body surface isopotential maps in normal children, ages 4 to 14 years. American Heart fournal, 72, 640.

Taccardi, B. (1963). Distribution of heart potentials on the thoracic surface of normal human subjects. Circulation Research, 12, 341.

Tazawa, H., and Yoshimoto, C. (1969). Electrocardiographic potential distributions in newborn infants from twelve hours to eight days after birth. American Heart fournal, 78, 292.

Wróblewski, F., and LaDue, J. S. (1955). Lactic dehydrogenase activity in blood. Proceedings of the Society for Experimental Biology and Medicine, 90, 210.

Requests for reprints to Dr. Andrzej Krotkiewski, Department I of Medicine, Central Clinical Hospital, 02-507 Warsaw, Komarowa 137, Poland. 